\title{
US and MDCT diagnosis of a rare cause of haematuria in children: Posterior nutcracker syndrome
}

\author{
A. Ozel ${ }^{a, *}$, O. Tufaner $^{\text {a }}$, E. Kaya ${ }^{a}$, V. Maldur ${ }^{b}$ \\ a Department of Radiology, Sisli Etfal Research and Training Hospital, Istanbul, Turkey \\ b Department of Radiology, Policlinico Umberto I, University 'La Sapienza', Rome, Italy
}

\section{KEYWORDS}

Nutcracker syndrome;

Ultrasound;

Doppler;

MDCT.

\begin{abstract}
Posterior nutcracker syndrome is caused by compression of the left renal vein between the abdominal aorta and the vertebral column. We present the case of a 14-yearold girl with vague left loin pain, mild haematuria and proteinuria. Diagnosis of this rare syndrome was achieved using color Doppler US and multidetector computed tomography (MDCT) angiography.
\end{abstract}

Sommario La sindrome da schiaccianoci posteriore è dovuta alla compressione della vena renale sinistra tra l'aorta addominale e la colonna vertebrale. Viene presentato il caso di una ragazza di 14 anni con lombalgia sinistra, lieve ematuria e proteinuria, in cui la diagnosi di questa rara sindrome è stata ottenuta con Eco-color Doppler e con l'Angio-TC.

(c) 2011 Elsevier Srl. All rights reserved.

\section{Introduction}

The term nutcracker syndrome (NCS) was first used by the Belgian physician de Schepper to describe compression of the left renal vein between the aorta and the superior mesenteric artery resulting in elevated pressure in the left renal vein and haematuria due to the development of collateral veins [1]. This syndrome has also been reported in association with retroaortic course of the left renal vein between the aorta and the vertebral column and has been termed as posterior NCS [2]. We report the ultrasound (US)

\footnotetext{
* Corresponding author. Department of Radiology, Sisli Etfal Research and Training Hospital, 34377 Sisli-Istanbul, Turkey.

E-mail address: dralperozel@gmail.com (A. Ozel).
}

and multidetector computed tomography (MDCT) findings in a 14-year-old girl with posterior NCS.

\section{Case report}

A 14-year-old girl was referred to our department by the clinic of paediatric nephrology for vague left loin pain. Physical examination was unremarkable. Urine analysis revealed mild haematuria ( 5 red blood cells per high power field on microscopy) and apparently mild proteinuria $(+)$. However, daily urine protein excretion was significant $(2.293 \mathrm{~g} /$ day; reference value $0.022-0.150 \mathrm{~g} /$ day $)$. Blood urea and creatinine levels were within normal limits $(26 \mathrm{mg} /$ $\mathrm{dl}$ and $0.63 \mathrm{mg} / \mathrm{dl}$, respectively). US showed that both right and left kidney length, measured on the longest dimension, was within normal range, and parenchymal echogenicity as well as parenchymal thickness were normal. Transverse 

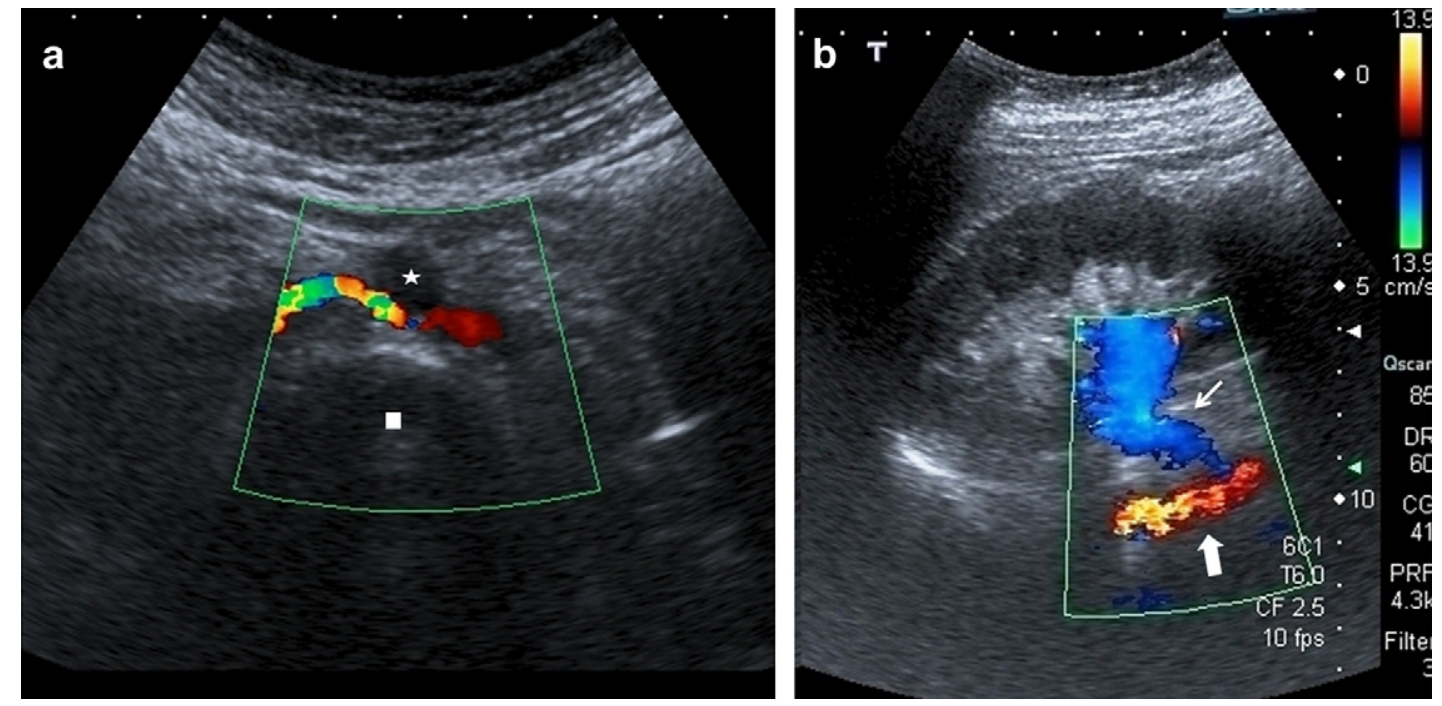

Fig. 1 a. Transverse midabdominal and coronal Doppler sonographic view of the left kidney (b). Image 1a shows the retroaortic course of the left renal vein. Constriction of the left renal vein between the aorta $(\star)$ and vertebra ( $\boldsymbol{\square})$ is evident. On image $b$, the proximal dilated portion of the left renal vein (arrow) and aorta (thick arrow) is evident.

midabdominal grey scale and Doppler US examination showed that the course of the left renal vein was between the aorta and the vertebral column (Fig. 1). The left renal vein was dilated at the renal hilum and significantly narrowed at the retroaortic segment (Fig. 2). Posterior NCS was suggested as the initial diagnosis. As US revealed compression of the left renal vein between the aorta and vertebral column, MDCT angiography was performed confirming the initial US diagnosis. It was decided that the patient should undergo conservative follow up.
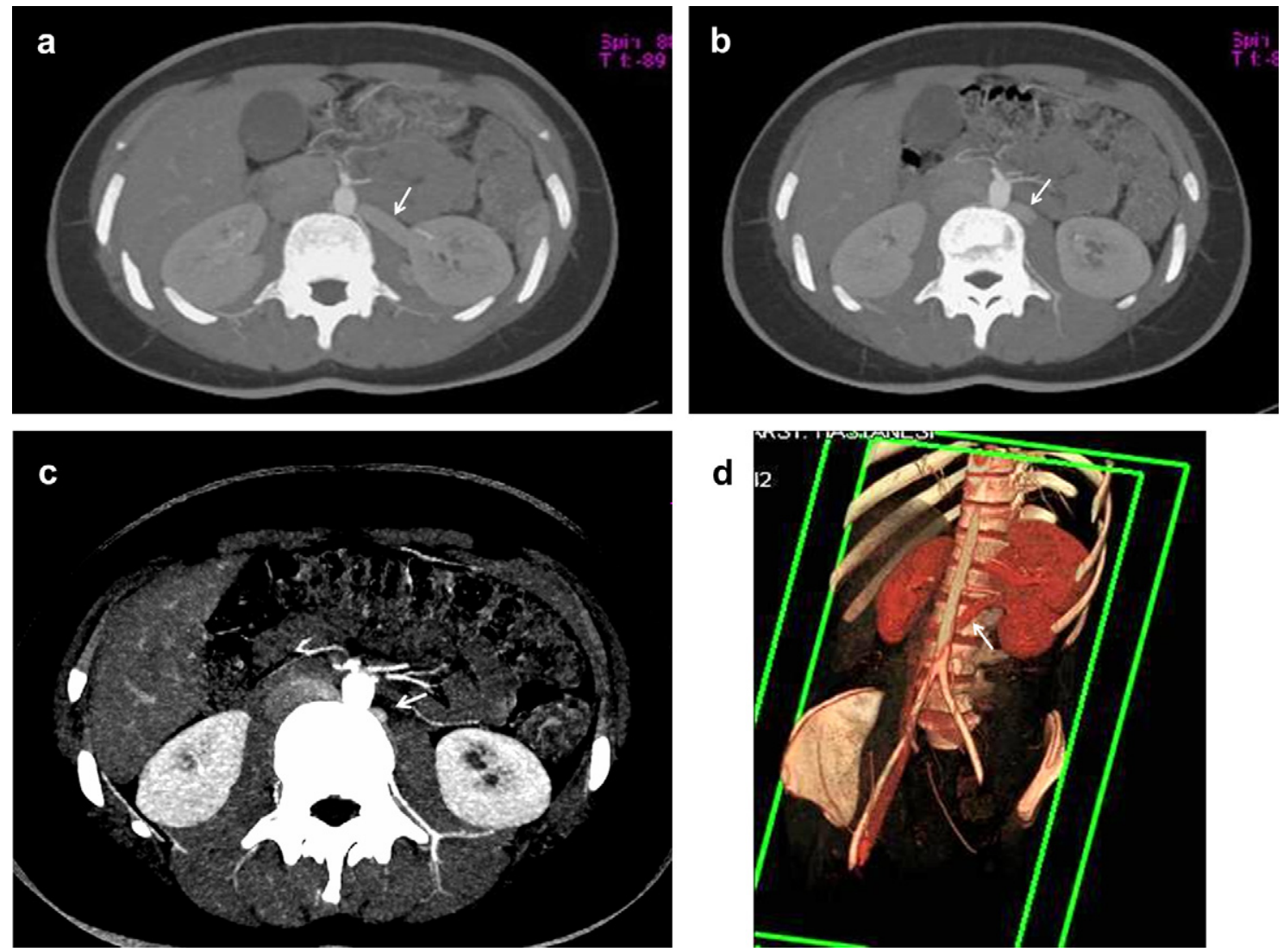

Fig. 2 Contrast enhanced CT images $(a-c)$ and 3D volume rendered image (d) showing the course of the left renal vein. On images a, b and d, the proximal dilation is evident (arrows). On c; compression of the left renal vein between the aorta and vertebral column is evidenced (arrow). 
Written informed consent was obtained from the patient's parents for the publication of this case report and accompanying images.

\section{Discussion}

NCS refers to the compression of the left renal vein by the adjacent anatomic structures. Anterior NCS arises due to an abnormal branching pattern of the superior mesenteric artery with an acute aortomesenteric angle [3-5]. Posterior NCS occurs when the left renal vein is compressed due to the decreased space between the aorta and the vertebral column $[3,6]$.

Clinical manifestations mainly include left flank and abdominal pain, with or without haematuria. Haematuria is caused by rupture of the thin walled septae between the well-developed collaterals such as the renal pelvic and ureteric collaterals and the renal pelvis [7]. Orthostatic and recumbent proteinuria have also been described. In females "pelvic congestion syndrome" is characterized by symptoms of dysmenorrhea, dyspareunia, postcoital ache, dysuria, pelvic, vulvar, gluteal and thigh varices; and in males varicocele is a common manifestation of NCS.

Renal phlebography using pressure gradient measurements used to be chosen as the diagnostic test for nutcracker syndrome [3,6]. However, due to the overlap between normal and elevated pressure values, and also due to the invasive nature of the method, other diagnostic modalities are now preferred [3]. Real time US and Doppler scanning may be employed as the initial diagnostic test in patients with suspected nutcracker syndrome. Measurement of the diameter and the peak velocities of the left renal vein at two points, i.e. at the renal hilum and at the superior mesenteric artery crossing point, was reported by Kim et al. as a successful method for the diagnosis of anterior nutcracker syndrome [8]. According to their study, a ratio of anteroposterior diameter and peak velocity greater than 5.0 show the sensitivity of $80 \%$, specificity of $94 \%$ and diagnostic accuracy of $83 \%$ [8]. However, no criteria related to diameter and peak velocity of the left renal vein in posterior NCS are reported in the literature. Nevertheless, in the present case US and Doppler scanning evidenced the retroaortic course and compressed segment of the left renal vein between the aorta and vertebra.

MDCT angiography confirms the anatomical relation between the left renal vein and the adjacent structures in anterior and posterior NCS [4]. The disadvantage of MDCT is radiation exposure, but the method is noninvasive and has been shown to have a superior diagnostic yield. MDCT angiography of the abdomen may demonstrate a left renal vein stricture with collateral circulation due to NCS in patients with no urinary symptoms. A distended left renal vein was reported in $72 \%$ of asymptomatic patients undergoing MDCT [9]. Likewise, stenosis was detected in $82 \%$ of left retroaortic renal veins. According to a recent study,
MDCT can demonstrate compression of the left renal vein in the aortomesenteric region and also delineate structures such as the diaphragmatic crus, pancreas, splenic vein or duodenum as the causes of left renal vein compression.

In conclusion, NCS is a rare cause of haematuria and proteinuria in children. Doppler US and MDCT angiography should be used as noninvasive imaging modalities to demonstrate the course and constricted segment of the left renal vein.

\section{Conflict of interest statement}

The authors have no conflict of interest.

\section{Appendix \\ Supplementary material}

Supplementary data related to this article can be found online at doi:10.1016/j.jus.2011.04.003.

\section{References}

[1] de Schepper A. "Nutcracker" phenomenon of the renal vein and venous pathology of the left kidney. J Belge Radiol 1972; 55:507-11.

[2] Lau JL, Lo R, Chan FL, Wong KK. The posterior nutcracker. Haematuria secondary to retroaortic left renal vein. Urology 1986;28:437-9.

[3] Hohenfellner M, Steinbach F, Schultz-Lampel D, Schantzen W, Walter K, Cramer BM, et al. The nutcracker syndrome: new aspects of pathophysiology, diagnosis and treatment. J Urol 1991;146(3):685-8.

[4] Shokeir AA, El-Diasty TA, Ghoneim MA. The nutcracker syndrome: new methods of diagnosis and treatment. Br J Urol 1994;74:139-43.

[5] Shaper KR, Jackson JE, Williams G. The Nutcracker Syndrome: an uncommon cause of haematuria. Br J Urol 1994;74:144-6.

[6] Ali-El-Dein B, Osman Y, Shehab El-Din AB, El-Diasty T, Mansour O, Ghoneim MA. Anterior and posterior nutcracker syndrome: a report on 11 cases. Transplant Proc 2003;35:851-3.

[7] Puig S, Stühlinger HG, Domanovits H, Staudenherz A, Zebenholzer K, Rebhandl W, et al. Posterior "nutcracker" phenomenon in a patient with abdomınal aortic aneurysm. Eur Radiol 2002;12:133-5.

[8] Kim SH, Cho SW, Kim HD, Chung JW, Park JH, Han MC. Nutcracker syndrome: diagnosis with Doppler US. Radiology 1996;198:93-7.

[9] Buschi AJ, Harrison RB, Norman A, Brenbridge AG, Williamson BR, Gentry RR, et al. Distended left renal vein: CT/sonographic normal variant. AJR Am J Roentgenol 1980; 135:339-42. 